\title{
Effect of gliadin and other food peptides on expression of MHC class II molecules by HT-29 cells
}

T Mothes, U Bendix, C Pfannschmidt, I Lehmann

\begin{abstract}
Expression of major histocompatibility (MHC) class II molecules by enterocytes is known to be enhanced in coeliac disease and other disorders characterised by intestinal inflammation - an effect thought to be mediated via intestinal lymphocytes. To investigate if food peptides can exert direct effects on class II expression, the influence of gliadins, casein, and $\beta$ lactoglobulin on an intestinal epithelial cell line (HT-29) was examined in the absence of immune cells. Class II expression was determined by flow cytometry and immunofluorescence microscopy using antibodies against the $\beta$ chain of all products of the gene subregions $D R, D Q$, and DP. MHC expression was low in HT -29 cells but could be stimulated by interferon $\gamma$. Tryptin digested gliadin had no effect on class II expression. In the presence of interferon $\gamma$, however, it was able to amplify MHC class II expression to mean (SEM) 150 (4)\%. Casein exerted a similar effect (160 (14)\%), but undigested gliadin, tryptin digested casein, and $\beta$ lactoglobulin had no influence. The observations suggest that within the concert of cytokine mediated interactions between enterocytes and lymphocytes, some dietary peptides could upregulate the presentation of food antigens, leading to a more efficient stimulation of lymphocytes, which in the case of coeliac disease might result in damage to the enterocytes. (Gut 1995; 36: 548-552)
\end{abstract}

Keywords: gliadin, casein, $\beta$ lactoglobulin, interferon $\gamma$, enterocytes, HT-29 cells, MHC.

Institute of Clinical Chemistry and Pathological Biochemistry and Institute of Clinical Immunology, Department of Medicine, University of Leipzig, Germany $T$ Mothes C Bendix I Lehmann

Correspondence to: Dr T Mothes, Institute of Clinical Chemistry and Pathological Biochemistry, Department of Medicine, University of Leipzig, Germany.

Accepted for publication 15 July 1994
Expression of major histocompatibility class (MHC) antigens by enterocytes is known to be enhanced in coeliac disease and in other disorders characterised by intestinal inflammation such as ulcerative colitis and Crohn's disease.$^{1-6}$ In a wide variety of cells, including macrophages, $\mathrm{B}$ cells, and activated $\mathrm{T}$ cells, MHC class II molecules function as restriction elements in the presentation of antigenic peptides to lymphocytes. The role of class II molecules on intestinal enterocytes is less clear, but recent observations suggest that these cells may also be regarded as antigen presenting cells. ${ }^{7}$

In coeliac disease, it is known that wheat gliadins are responsible for the induction of the disorder. Hitherto, the effect of these food proteins on enhancement of MHC expression has been considered indirect ${ }^{5}$ - that is, mediated solely by lymphokines released from immune cells after antigenic stimulation. Therefore, the possibility that gliadin and other food derived peptides are able to exert a direct influence on the expression of MHC class II molecules was investigated.

For this purpose, expression of class II molecules was estimated in HT-29 cells, cultured in gliadin peptides. The HT-29 cell line was established from a human colon adenocarcinoma ${ }^{8}$ and has been shown capable of expressing MHC class II molecules after stimulation with interferon $\gamma(\gamma$-IFN $) .{ }^{910}$ In the human intestinal tract, class II antigen expression has also been found in colonic epithelial cells. ${ }^{4}$ The advantage of using an enterocytic cell line in these studies is that the influence of lymphocyte derived cytokines can be excluded enabling any direct effect of gliadin to be detected.

\section{Methods}

SUBSTANCES TESTED

Gliadin was obtained by ethanolic extraction of flour of wheat Compal (Saatzucht Meissen, Germany) according to ${ }^{11}$ and purified by ion exchange chromatography on DEAE cellulose as described. ${ }^{12}$ Altogether $100 \mathrm{mg}$ of purified gliadin (gli) was solubilised in $100 \mathrm{ml}$ TRIS buffer $(10 \mathrm{mmol} / \mathrm{l}, \mathrm{pH} 7 \cdot 0)$ containing $5 \mathrm{mg}$ trypsin (porcine pancreas, $55 \mathrm{U} / \mathrm{ml}$; Serva). After 18 hours incubation at $37^{\circ} \mathrm{C}$ the reaction was stopped by the addition of $100 \mathrm{ml}$ acetic acid $(1 \mathrm{~mol} / \mathrm{l})$, and the solution was ultrafiltrated (YM 30, Amicon). The non-ultrafiltrable protein was lyophilised (t-gli).

Casein (C-4032) and $\beta$ lactoglobulin (L-0130) were obtained from Sigma. For digestion of casein a similar procedure of trypsin treatment was followed. Interferon $\gamma$ ( $\gamma$-IFN; human, recombinant) was obtained from Boehringer Mannheim.

The molecular weight of the polypeptides in the different gliadin and casein preparations and of $\beta$ lactoglobulin was estimated by sodium dodecylsulphate polyacrylamide gel electrophoresis (SDS-PAGE) as described ${ }^{13}$ in $14 \%$ gels followed by staining with Coomassie brilliant blue R-250.

\section{CELL CULTURE}

The human colonic adenocarcinoma cell line $\mathrm{HT}-29$ was maintained at $37^{\circ} \mathrm{C}$ in a 


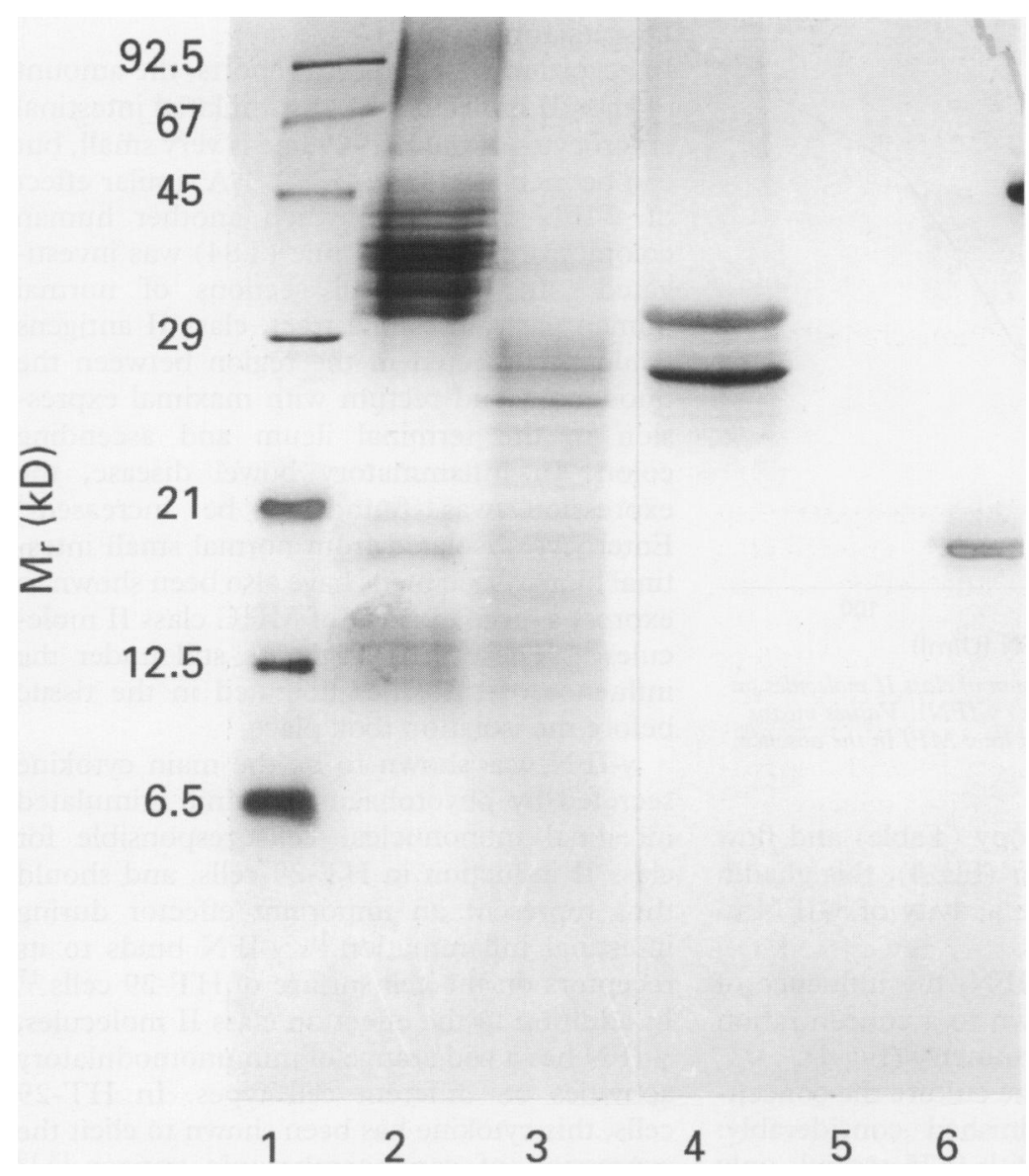

Figure 1: SDS-PAGE estimation of the different test polypeptides used. Lane 1 - molecular weight marker proteins; 2 - purified gliadin; 3 - gliadin; 4 - casein;

5 - tryptin digested casein; 6 - $\beta$ lactoglobulin.

humidified atmosphere of $5 \% \quad \mathrm{CO}_{2}$ in DMEM (Serva) supplemented with $10 \%$ fetal calf serum, HEPES (10 mmol/l), nonessential amino acids (1\%; Serva), glutamine (2 mmol/l), $\mathrm{NaHCO}_{3}(10 \mathrm{mmol} / \mathrm{l})$, mercaptoethanol $(50 \mu \mathrm{mol} / \mathrm{l})$, and gentamycin $(200 \mathrm{mg} / \mathrm{l})$. After trypsinisation, HT-29 cells were applied to 24 -well tissue culture plates $\left(0.35 \times 10^{5}\right.$ cells in $1.25 \mathrm{ml}$ culture medium/well). After 24 hours, fresh medium was added containing the substances $(\gamma$-IFN, gli, control peptides) to be tested and the cells were cultured for further 120 hours. After that, the cells were harvested by trypsin treatment, washed, and resuspended in phosphate buffered saline (PBS).

\section{ANALYSIS OF CLASS II EXPRESSION}

For flow cytometry, $100 \mu$ l of a suspension containing $2 \times 10^{5}$ cells were incubated for 15 minutes at room temperature with $10 \mu \mathrm{l}$ of FITC-conjugated monoclonal mouse antihuman HLA-DR antibody (CR3/43, Dakopatts), fixed for 10 minutes at room temperature in FACS lysing solution (Becton Dickinson) was washed three times in PBS. The cells were then resuspended in $250 \mu$ l fixing buffer (1\% formalin in PBS). Fluorescence intensity was measured using a FACSscan analyser (Becton Dickinson, Belgium). The cells were acquired and analysed using LYSIS II software. The density of expression of the class II molecules was given as relative mean fluorescence intensity (MFI) with MFI under control conditions set $100 \%$. As a negative control an isotype (IgG1) matched FITC-conjugated monoclonal mouse antibody (code DAKO X 927, Dakopatts) was used.

For fluorescence microscopy, $50 \mu l\left(10^{6}\right)$ washed cells were incubated for 30 minutes at room temperature with $25 \mu l(1: 50)$ of monoclonal mouse anti-human HLA-DR (CR3/43, Dakopatts) and washed three times in PBS again. The sedimented cells were incubated with $25 \mu l$ (1:25) of FITCconjugated rabbit anti-mouse immunoglobulins (Dakopatts). After incubation for 30 minutes at room temperature, the cells were washed in PBS, resuspended in $20 \mu \mathrm{l}$ mounting medium (PBS:glucerine $=2: 1$ ), and the fraction of cells showing surface membrane fluorescence was determined using a microscope (Axioskop, Carl Zeiss Oberkochen, Germany).

\section{ENZYME IMMUNOASSAY OF GLIADIN}

Gliadin containing culture medium was diluted with carbonate buffer $(0 \cdot 1 \mathrm{M}, \mathrm{pH}$ 9.5). Microtitre plates (Linbro) were coated with $100 \mu$ l of diluted culture medium. The cavities were washed in TRIS buffered saline (TBS, $150 \mathrm{mM} \mathrm{NaCl}, 10 \mathrm{mM}$ TRIS, 0.05\% Tween 20, pH 10.2), blocked (TBS containing $1 \%$ Tween 20 ), washed again in TBS, and incubated for two hours at $37^{\circ} \mathrm{C}$ with $100 \mu \mathrm{l}$ (1:750) rabbit anti-gli. ${ }^{12}$ After that the wells were washed again and incubated for 90 minutes at $37^{\circ} \mathrm{C}$ with $100 \mu l(1: 1500)$ goat anti-rabbit immunoglobulins, conjugated with alkaline phosphatase (Dakopatts). After washing again the enzyme activity was measured using p-nitrophenylphosphate as a substrate.

DETERMINATION OF LACTATE DEHYDROGENASE This was performed in media according to Laemmli ${ }^{13}$ after the cells had been cultured for 120 hours in the presence of varying concentrations of $\gamma$-IFN.

\section{Results}

SDS-PAGE patterns of gli, t-gli, casein, and $\beta$ lactoglobulin are shown in Fig 1. Tryptin digested casein could not be detected (molecular weight $<4 \mathrm{kD}$ ).

By means of direct as well as indirect immunofluorescence it could be shown that $\gamma$-IFN induces the expression of class II molecules in HT-29 cells. The increase in HLA molecules occurred in a concentration dependent manner (Fig 2).

Release of lactate dehydrogenase, a measure of cell viability, ${ }^{15}$ is enhanced by treatment with $\gamma$-IFN (Fig 3), pointing to the cy,totoxic effect of this cytokine. In the following experiments, therefore, only a $\gamma$-IFN concentration of $16 \mathrm{U} / \mathrm{ml}$ was used.

T-gli is not able to stimulate the expression of class II molecules in the absence of $\gamma$-IFN. 


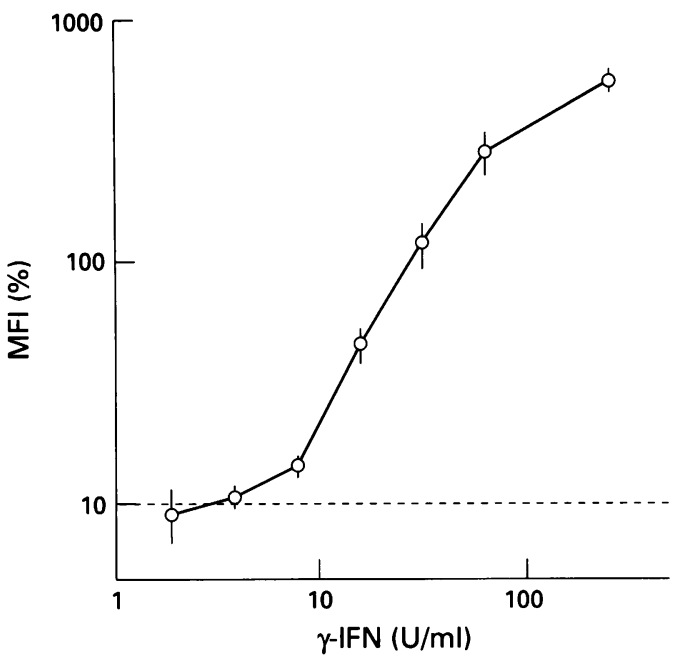

Figure 2: Dependence of expression of class II molecules on the concentration of interferon $\gamma(\gamma-I F N)$. Values means (SEM) of three cultures. Dotted line: MFI in the absence of $\gamma-I F N$.

As fluorescence microscopy (Table) and flow cytometry show, however (Fig 4), this gliadin preparation increases the activity of $\gamma$-IFN to induce class II molecules.

In the presence of $\gamma$-IFN, the influence of t-gli can be detected down to a concentration of $0.01 \mathrm{mg} / \mathrm{ml}$ by flow cytometry (Fig 4 ).

During the course of the culture the concentration of t-gli is diminished considerably: five days after starting with $0.25 \mathrm{mg} / \mathrm{ml}$, only $0.09 \mathrm{mg} / \mathrm{ml}$ was demonstrable by enzyme immunoassay. Therefore in a series of experiments, fresh culture medium (containing the original concentration of $\gamma$-IFN and t-gli) was used to replace the old one after two days. The effect of t-gli on MHC expression, however, was not increased under these conditions (results not shown).

In contrast with t-gli, the non-hydrolysed gli did not influence MHC expression. The same was true for the control peptide $\beta$ lactoglobulin. Casein, however, showed an effectivity comparable with t-gli, which could be diminished strongly by tryptin treatment (Fig 4).

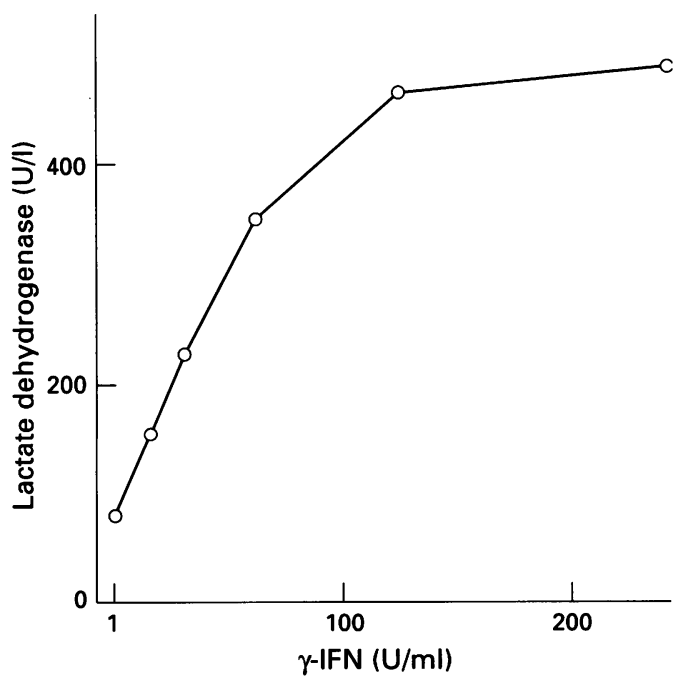

Figure 3: Effect of interferon $\gamma(\gamma-I F N)$ on the release of lactate dehydrogenase from $H T-29$ cells. (Representative of a typical experiment.)

\section{Discussion}

In accordance with recent reports, the amount of class II molecules in unstimulated intestinal enterocytes of the HT-29 line is very small, but can be increased by $\gamma$-IFN. ${ }^{9}{ }^{10}$ A similar effect of $\gamma$-IFN was found when another human colonic carcinoma cell line (T84) was investigated. ${ }^{4}$ In histological sections of normal human gastrointestinal tract, class II antigens could be detected in the region between the duodenum and rectum with maximal expression in the terminal ileum and ascending colon. In inflammatory bowel disease, the expression was found to be increased. ${ }^{4}$ Enterocytes isolated from normal small intestinal biopsy specimens have also been shown to express a large number of MHC class II molecules. ${ }^{13}$ These cells might be still under the influence of cytokines liberated in the tissue before the isolation took place.

$\gamma$-IFN was shown to be the main cytokine secreted by phyotohaemagglutinin stimulated intestinal mononuclear cells responsible for class II induction in HT-29 cells, and should thus represent an important effector during intestinal inflammation. ${ }^{16} \gamma$-IFN binds to its receptors on the cell surface of HT-29 cells. ${ }^{17}$ In addition to the effect on class II molecules, $\gamma$-IFN has a wide range of immunomodulatory activities on different cell types. In HT-29 cells, this cytokine has been shown to elicit the expression of carcinoembryonic antigen, ${ }^{18} 19$ intercellular adhesion molecule- $1,{ }^{20}$ and secretory component. ${ }^{21}$ The mechanism of signal transduction after binding of $\gamma$-IFN remains unclear.

The antibodies used to detect HLA molecules react with the $\beta$ chain of all products of the gene subregions DP, DQ, and DR (class II molecules). DR molecules were found to be the predominant class II antigens, followed by DP, when normal histological sections of the intestine $^{4}$ or isolated human enterocytes ${ }^{15}$ were investigated. With regard to HT-29 cells, it is known from previous investigations that DR antigens preferentially, and after a delay of several days DQ antigens too, can be expressed by HT-29 cells. ${ }^{10}$ Thus the measured signal should be mainly due to DR and DQ molecules.

The results show that in the presence of $\gamma$-IFN, gliadin and casein are able to amplify MHC expression in HT-29 cells. To make these peptides effective, an optimal molecular weight is necessary: gliadin is active only when treated with trypsin, but inactive when it is applied in its native undegraded form, whereas casein is effective only in the undigested form.

Because of the restricted number of lys and arg residues in gli, ${ }^{22}$ treatment of gli with trypsin results in relatively large peptides (4-30 kD). These are subsequently subjected to further proteolysis by enterocytic enzymes, however, so that after only a few days of culture less than $50 \%$ of the gliadin peptides initially applied could be recognised by immunoassay. In keeping with the effect on MHC expression, tryptin digested gliadin preparations obtained by slightly different methods have been described as toxic for 
Influence of trypsin digested purified gliadin ( $t$-gli) on fraction of $H T-29$ cells showing surface fluorescence (in \%). Means of two experiments are given in which cells in more than 20 visual fields were counted.

\begin{tabular}{cccc}
\hline & \multicolumn{3}{l}{$t$-gli $(\mathrm{mg} / \mathrm{ml})$} \\
\cline { 2 - 4 }$(U / \mathrm{ml})$ & 0.00 & $0 \cdot 10$ & $0 \cdot 25$ \\
\hline 0 & 0 & 0 & 0 \\
16 & 44 & 58 & 85 \\
\hline
\end{tabular}

coeliac patients ${ }^{23}$ as well as for fetal chick intestine in tissue culture, a test system for the toxic action of gliadins. ${ }^{24}$

The inability of native gliadin $(10-45 \mathrm{kD})$ to provoke an amplification of MHC expression might be taken as an indication that, at least under culture conditions, active split products like those obtained after tryptin digestion could not be formed.

Unlike gliadin, casein is active only in the undigested form and the effect is lost during tryptin treatment. It must be remembered that the molecular weight of undigested casein peptides $(10-30 \mathrm{kD})$ is already in the range of that of t-gli, whereas after tryptin treatment small peptides $(<4 \mathrm{kD})$ are produced. This shows that proteolytic degradation into small peptides abolishes the effect on MHC molecules.

Because casein has been reported to be less resistant to pancreatic proteases than gliadin, ${ }^{25} 26$ undigested casein may not play an important part in MHC expression under physiological conditions. In relation to gliadin, however, recent findings ${ }^{27} 28$ suggest that gliadin peptides are incompletely digested in the intestinal lumen of coeliac patients and thus remain available for toxic action on the intestinal mucosa.

The inactivity of $\beta$ lactogloblin, the molecular weight of which is between 18 and $20 \mathrm{kD}$ and thus comparable with that of the effective peptides of casein and of t-gli, suggests that the enhancement of MHC expression may not be a general property of food peptides. It should be the aim of future investigations to clarify the specificity of the effect.

The results suggest that in addition to

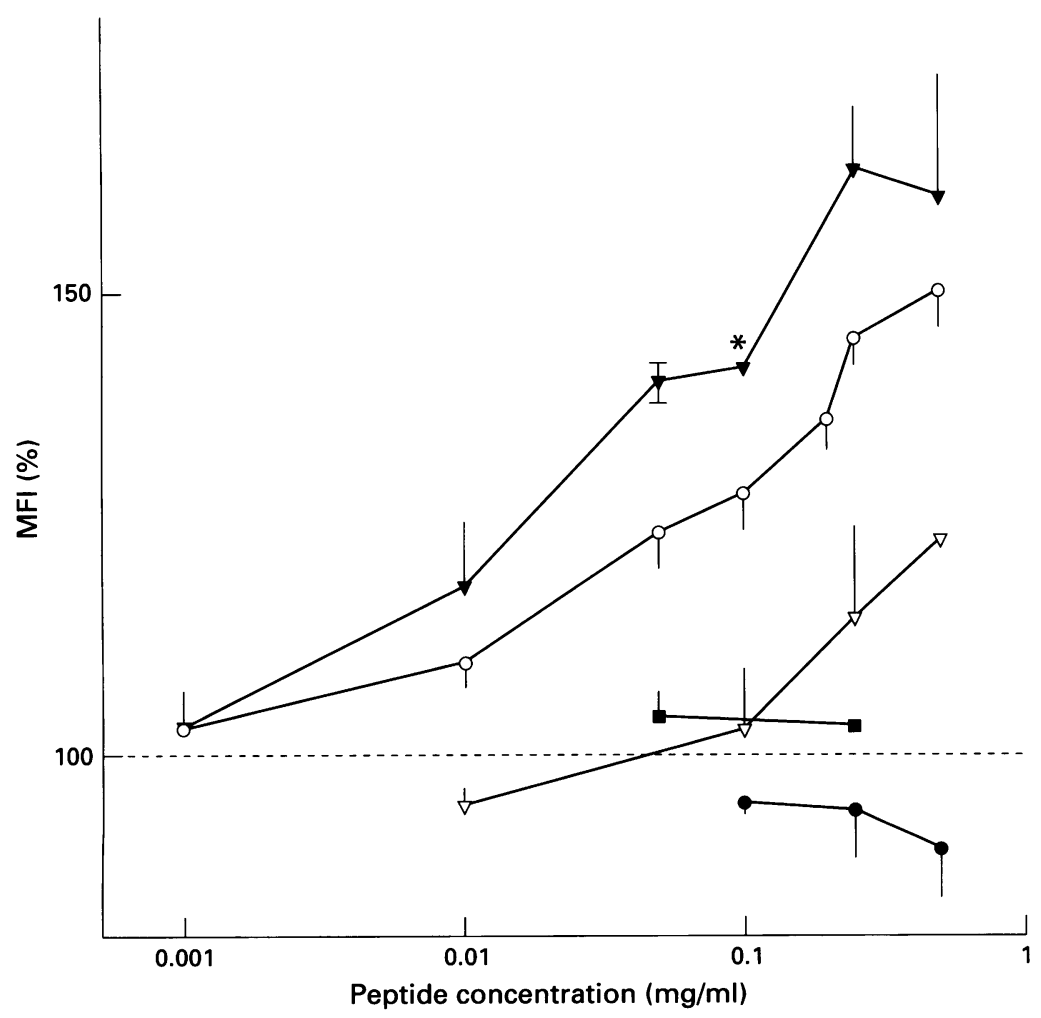

Figure 4: MHC expression by HT-29 cells - influence of purified gliadin gli (O), tryptin digested gliadin ( $O)$, casein $(\nabla)$, tryptin digested casein $(\nabla)$, and $\beta$ lactoglobulin ( $\square$ ). Culture in the presence of interferon $\gamma$ without addition of food derived peptides was $100 \%$. Means of three to four ( $t$-gliadin, four to seven) individual cultures are shown (* only two cultures performed). For sake of clarity the SEM is given in only one direction. mucosal lymphocytes, ${ }^{29}$ enterocytes may take part in the processes of antigen presentation in the intestine. Within the concert of cytokine mediated interactions between enterocytes and lymphocytes, gliadin peptides (and possibly other food derived peptides too) could upregulate the presentation of food antigens and perhaps their own presentation too. This process could lead to a more efficient stimulation of lymphocytes, which, in the case of coeliac disease, ultimately results in damage to the enterocytes. The molecular nature of the effect of food peptides on MHC expression on intestinal epithelial cells in the presence of $\gamma$-IFN remains to be clarified.

This work was supported by a grant of Deutsche Forschungsgemeinschaft (no 572/1-1).

The authors thank Mrs A Zeun for excellent technical assistance.

1 Ciclitira PJ, Nelufer JM, Ellis HJ, Evans DJ. The effect of gluten on HLA-DR in the small intestinal epithelium of patients with coeliac disease. Clin Exp Immunol 1986; 63: patients

2 Scott H, Sollid LM, Brandtzaeg P. Expression of MHC class II determinants by jejunal epithelium in coeliac disease. F Pediatr Gastroenterol Nutr 1988; 7: 145-6.

3 Arnaud-Battandier F, Cerf-Bensussan N, Amsellem R Schmitz J. Increased HLA-DR expression by enterocytes in children with coeliac disease. Gastroenterology 1986; 91 1206-12.

4 Mayer L, Eisenhardt D, Salomon P, Bauer W, Plous R Piccinini L. Expression of class II molecules in intestina epithelial cells in humans. Differences between norma and inflammatory bowel disease. Gastroenterology 1991; 100: 3-12.

5 Fais S, Maiuri L, de Vincenzi M, de Ritis G, Troncone S. Gliadin induced changes in the expression of MHC-class II antigens by human small intestinal epithelium. Organ culture studies with coeliac disease mucosa. Gut 1992; 33: $472-5$.

6 Selby WS, Janossy G, Mason DW, Jewell DP. Expression of HLA-DR antigens by colonic epithelium in inflammatory bowel disease. Clin Exp Immunol 1983; 53: 614-8.

7 Bland P. MHC class II expression by the gut epithelium. Immunol Today 1988; 9: 174-8.

8 Fogh J, Trempe G. New human tumor cell lines. In: Fogh J ed. Human tumor cells in vitro. New York: Plenum Publishing, 1975: 115-41.

9 Schwartz R, Momburg F, Moldenhauer G, Dörken B, Schirrmacher $V$. Induction of HLA class-II antigen expression on human carcinoma cell lines by IFNgamma. Int $\mathcal{f}$ Cancer 1985; 35: 245-50.

10 Sollid LM, Gaudernack G, Markussen G, Kvale D, Brandtzaeg P, Thorsby E. Induction of various HLA class II molecules in a human colonic adenocarcinoma cell line. Scand F Immunol 1987; 25: 175-80.

11 Patey AL, Evans DJ. Large-scale preparation of gliadin proteins. I Sci Food Agric 1973; 24: 1229-33.

12 Osman A. Leipzig: University of Leipzig, 1992 Dissertation.

13 Laemmli UK. Cleavage of structural proteins during the assembly of the head of the bacteriophage T4. Nature 1970; 227: $680-5$.

14 Deutsche Gesellschaft für Klinische Chemie. Z Klim Chem Klin Biochem 1972; 10: 182-5.

15 Madrigal L, Lynch S, Feighery C, Weir D, Kelleher D, O'Farelly C. Flow cytometric analysis of surface major histocompatibility complex class II expression on human histocompatibility complex class II expression on human epithelial cells prepared from small

16 Lowes JR, Radwan P, Priddle JD, Jewell DP. Characterisation and quantification of mucosal cytokine that induces epithelial histocompatibility locus antigen-DR expression in inflammatory bowel disease. Gut 1992; 33: 315-9.

17 Crotty B, Rosenberg WMC, Aronson JK, Jewell DP. Inhibition of interferon-gamma to its receptor by salicylates used in inflammatory bowel disease. Gut 1992; 33: 1353-7.

18 Bombardieri E, Cocciolo MG, Valtolina M, Giussani C, Ringhini R, Esposito G, et al. Effects of alpha, beta and gamma recombinant interferons on CEA production from HT-29 human colon adenocarcinoma cell line. $\mathcal{f}$ Biol Regul Homeost Agents 1987; 1: 133

19 Kantor J, Tran R, Greiner J, Pestka S, Fisher PB, Shively $\mathrm{JE}$, et al. Modulation of carcinoembryonic antigen $\mathrm{JE}$, et al. Modulation of carcinoembryonic antigen messenger RNA levels in human colon carcinoma cells by 49: $2651-5$.

20 Kelly CP, O'Keane JC, Orellana J, Schroy PC, Yang S, Lamont, et al. Human colon cancer cells express ICAM-1 in vivo and support LFA-1-dependent lymphocyte adhesion in vitro. Am f Physiol 1992; 263: G864-70. 
21 Sollid LM, Kvale D, Brandtzaeg P, Markussen G, Thorsby E. Interferon-gamma enhances expression of secretory component, the epithelial receptor for polymeric immunoglobulins. F Immunol 1987; 138: 4303-6.

22 Wieser H, Mödl A, Seilmeyer W, Belitz H-D. High-performance liquid chromatography of gliadins from differen wheat varieties: Amino acid composition and N-terminal amino acid sequence of components. $Z$ Lebensm Unters Forsch 1987; 185: 371-8

23 Hekkens WTJM, van den Aarsen CJ, Gilliams JP, Lems-van Kan P, Bouma-Frölich G. Gliadin structure and degradation. In: WTJM Hekkens, AS Peña, eds. Coeliac disease. Leiden: Stenfert Kroese, 1974: 39-45.

24 Mothes T, Mühle W, Müller F, Hekkens WTJM. Influence of gliadin on fetal chick intestine in tissue culture. of gliadin on fetal chick intes

25 Camus M-C, Laporte JC. Proteolyse in vitro de caseine et de gluten par les enzymes pancreatiques. Reprod Nutr Dev $1980 ; 20$ (4A): 1025-39.
26 Friedrich $M$, Noack J, Proll J, Noack R. Absorption of enzymatic protein hydrolysates and equimolar amino acid mixtures in the perfused small intestine of the rat. Biomed Biochim Acta 1984; 43: $117-30$

27 Cornell HJ. Mucosal digestion studies of whole gliadin fractions in coeliac disease. Ann Clin Biochem 1990; 27 44-9.

28 Cornell HJ, Auricchio RS, de Ritis G, de Vincenzi M, Maiuri L, Raia V, et al. Intestinal mucosa of celiacs in remission is unable to abolish toxicity of gliadin peptides on in vitro dev peptides on in vitro developing fetal rat intestine and 233-7.

29 Lundin KEA, Scott H, Hansen T, Paulsen G, Halstensen TS, Fausa $\mathrm{O}$, et al. Gliadin-specific, HLA-DQ (alpha $1^{\star} 0501$, beta $1^{\star} 0201$ ) restricted $T$ cells isolated from the small intestinal mucosa of celiac disease patients. f Exp Med 1993; 178: 187-96. 
key topics' category. It should be judged in these terms, of course, as it is not a textbook of paediatric gastroenterology. The authors of the chapters are well recognised names in the community of paediatric gastroenterologists, from North America and from the United Kingdom, with one representative from continental Europe. Predictably, all have undertaken their task competently and successfully.

The success of the publication must depend on the choice of topics included. This is good in the main, but at times somewhat specialist. The generalist who sees children with gastrointestinal problems will find the chapters on oral rehydration solution, constipation, food allergy, inflammatory bowe disease, gastro-oesophageal reflux, recurrent abdominal pain, and gastrointestinal bleeding, of great interest and educational value. The chapter on 'when to transplant the liver in children' fits uncomfortably; it is a very interesting question for the paediatric hepatologist or specialist gastroenterologist but of little relevance to the probable readership of the publication. The chapters on the role of gastrointestinal motility studies and of home parenteral nutrition fall in between, probably The relevance of the book to a reader wil depend on the number of children with these problems they see, and I suspect that the book will be most useful to the general paediatrician and not the general gastroenterologist

In keeping with the ethos of counting credits, I would rate this book as being worth three credits (assuming that most generalists would probably read six chapters, and perhaps spend half an hour on each). By doing this, they are probably learning more than by earning six credits by listening to the same authors giving lectures on the same topics, and in addition they have the book on their shelves afterwards. Paediatricians should put it on their reading list for next term, as should any general gastroenterologist who sees children.

S P DEVANE

\section{NOTES}

\section{Wilson's disease and Menkes' disease}

The 7th International Symposium on Wilson's disease and Menkes' disease will be held in Vienna, Austria on 25-27 August 1995. Further information from: Prof Dr Peter Ferenci, Department of International Medicine IV, Gastroenterology and Hepatology, Währinger Gürtel 18-20, A-1090 Vienna, Austria. Tel: (43 1) 404004741 ; fax: (43 1) 4040047350

\section{Neurogastroenterology}

An International Symposium on Neurogastroenterology will be held on 10-11 November 1995 in Rome, Italy. Further information from: Dr Enrico Corazziari, Cattedra di Gastroenterologia I, Clinica
Medica II, Policlinico Umberto I, V le del Policlinico, 00161, Rome, Italy. Tel/fax: 39 6-4469965

\section{Paediatric gastroenterology}

The 1st International Congress of Pediatric Gastroenterology will be held in Jaipur, India on 12-16 December 1995. Further information from: Dr Balvir S Tomar, Head, Department of Pediatric Gastroenterology, 4 Govind Marg, Jaipur, 302 004, India. Tel: 91141604040 or 605050 ; fax: 91141 563788

\section{Gastroenterology}

A Postgraduate Gastroenterology Course will be held in Oxford on 7-10 January 1996 Further information from: Dr D P Jewell, Gastroenterology Unit, Radcliffe Infirmary, Woodstock Road, Oxford OX2 6HE. Tel: 01865 224829; fax: 01865790792

\section{Inflammatory bowel disease}

The International Inflammatory Bowel Disease Symposium will be held in Chester on 14-16 April 1996. Further information from: Prof Jonathan M Rhodes, Department of Medicine, Liverpool University, L69 3BX. Tel: 0151706 3558; fax: 01517065802.

ABIM announcement regarding change in training requirements for certification in gastroenterology

The American Board of Internal Medicine announces a new policy requiring three years of accredited training in a gastroenterology fellowship programme.

This decision follows a lengthy review by the ABIM Subspecialty Board on Gastroenterology and has the support of the American Gastroenterological Association, the American College of Gastroenterology, the American Society of Gastrointestinal Endoscopy, the American Association for the Study of Liver Diseases, and the Gastroenterology Training Program Directors.

This new policy becomes effective for fellows entering gastroenterology fellowship training programmes in June 1996 and thereafter. Trainees who have questions about this policy should contact the American Board of Internal Medicine, 3624 Market Street, Philadelphia, Pennsylvania, 19104-2675, USA.

\section{Falk Symposia}

Details of Falk Symposia for 1995 and 1996 and the Basel Liver Week 1995 are now available. Further information from: Falk Foundatione V, Leinenweberstraße 5, Postfach 65 29, D-79041 Freiburg, Germany. Fax: 0761/13034-59.

\section{Sir Francis Avery Jones BSG Research Award 1996}

Applications are invited by the Education
Committee of the British Society of Gastroenterology who will recommend to Council the recipient of the 1996 Award. Applications (eighteen copies) should include:

(1) A manuscript (2 A4 pages only) describing the work conducted.

(2) A bibliography of relevant personal publications.

(3) An outline of the proposed content of the lecture, including title.

(4) A written statement confirming that all or a substantial part of the work has been personally conducted in the UK or Eire.

Entrants must be 40 years or less on 31 December 1996 but need not be a member of the BSG. The recipient will be required to deliver a 40 minute lecture at the Spring meeting of the Society in 1996. Applications (eighteen copies) should be made to: The Honorary Secretary, BSG, 3 St Andrews Place, London NW1 4LB by 1 December 1995.

\section{CORRECTIONS}

The authors (Van't Hof et al Gut 1995; 36: 691-5) omitted an acknowledgement from their paper and would like to gratefully acknowledge the support of the Medical Research Council, South Africa.

An authors' error occurred in the paper by Khulusi et al (Gut 1995; 36: 193-7). The second sentence under Clinical Methods should read 'One duodenal biopsy was obtained from the ulcer margin and two from the anterior duodenum', and on the same point the second paragraph of the Discussion should re-affirm that the three duodenal bulb biopsy specimens included 'two from the anterior wall'

Some editorial errors occurred in the paper by Mothes et al (Gut 1995; 36: 548-52). The tenth line of the Methods section should read 'was stopped by the addition of $10 \mathrm{~m}$ acetic acid' and not $100 \mathrm{ml}$. In the legend to Fig 1: lane 2 should read 'gliadin (gli)' and not 'purified gliadin', lane 3 should read 'tryptic digested gliadin (t-gli)' and not 'gliadin'. The abscissa to Fig 3 should begin with zero and not 1 . The legend to Fig 4 should read 'MHC expression by HT-29 cells - influence of gliadin (gli) ( $\bullet$ ), tryptic digested gliadin (t-gli) $(0)$, casein $(\boldsymbol{\nabla})$, tryptic digested casein $(\nabla)$, and $\beta$ lactoglobulin $(\boldsymbol{\square})$ Culture in the presence of interferon $\gamma$ without addition of food derived peptides was $100 \%$. Means of three or four ( $t$-gli, four to seven) individual cultures are shown (^only two cultures performed). For sake of clarity the SEM is given in only one direction'.

Also, 'trypsin' and 'tryptic digestion' has been printed as 'tryptin' and tryptin digestion' throughout the text. 